\title{
Photochromism of a new symmetrical diarylethene with a trimethylsilylacetylene unit
}

\author{
Xiaoxia Zhang ${ }^{1}$, Renjie Wang ${ }^{1^{*}}$ and Shouzhi $\mathrm{Pu}^{1}$ \\ ${ }^{1}$ Jiangxi Key Lab of Organic Chemistry, Jiangxi Science and Technology Normal University, \\ Nanchang 330013, China. \\ *bio-wrj@163.com
}

Keywords: Photochromism, Diarylethene, Fluorescence switching, Trimethylsilylacetylene

\begin{abstract}
A new symmetrical photochromic diary lethene 1, 2 -bis ( 2 - menthy l-5 -( trImethyls ilylacetylene)-3 -thienyl) perfluorocyclopentene (10) based on a dithiophene structure has been constructred, and the photochromic and fluorescent properties of 1 were investigated. The results indicated diarylethene 1o showed good photochromism and notable fluorescence switching, which make it possible potential application in optical recording.
\end{abstract}

\section{Introduction}

During the past decade, a number of works were focused on the photochromic compounds due to their potential applications in optical switches and memories [1-4]. Since the development of the photochromic compounds, diarylethenes have drawn greater attention on photocontrollable elements in molecular devices and switches [5-6] Because of their distinguished thermal stability [7] and remarkable fatigue [8] resistance of the cyclization and cycloreversion reactions, Photochromic materials can reversibly interconvert between open ring and closed ring conformations [9]. Up to now, some researches about photochromic diarylethenes containing heteroaryl moieties including benzothiophene, benzofuran, thiophene, thiazole, pyrrole, benzene, pyridine, and indole [10] have been put into effect. Morever, diarylethene derivatives bearing a dithiophene skeleton is the most promising because either the open ring or the closed ring isomer exhibits excellent properties ahout thermal stability, fatigue resistance, response and reactivity in solution[11]. However, the study about diarylethene bearing a dithiophene skeleton is extremely rare reported.

In the present report, we synthesized a photochromic symmetrical diarylethene 10 with good photochromism and fluorescence. Scheme 1 shows the photochromic reaction of diarylethene $1 o$.

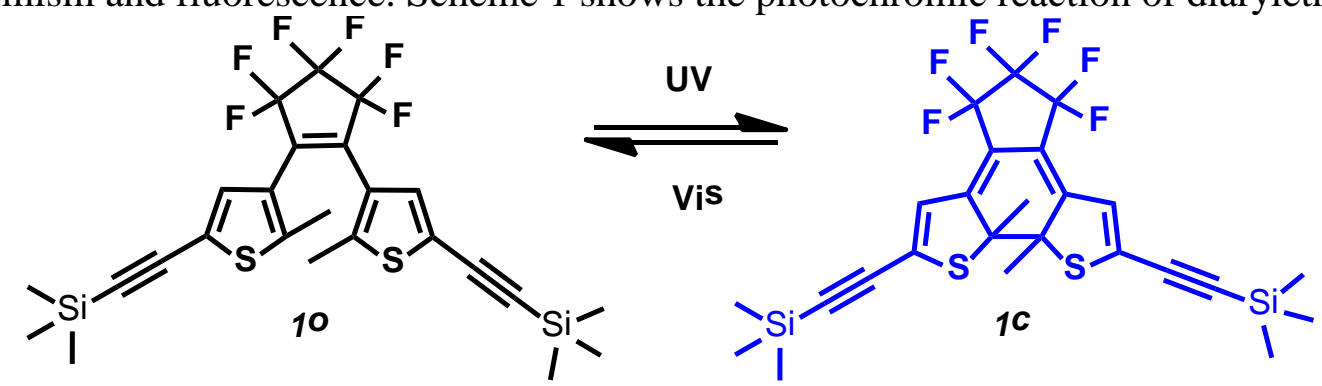

Scheme 1. Photochromism of 10

\section{Experiment}

The synthetic route used to obtain 10 is shown in Scheme 2. 10 was facilely synthesized as a canary solid with a $52 \%$ yield by the method in some literatures [2, 11]. ${ }^{1} \mathrm{H}$ NMR (400 $\left.\mathrm{MHz}, \mathrm{CDCl}_{3}\right), \delta$ (ppm): 0.27 (s, 18H, $\left.-\mathrm{CH}_{3}\right), 1.90\left(\mathrm{~s}, 6 \mathrm{H},-\mathrm{CH}_{3}\right), 7.22$ (s, 2H, thiophene-H). 


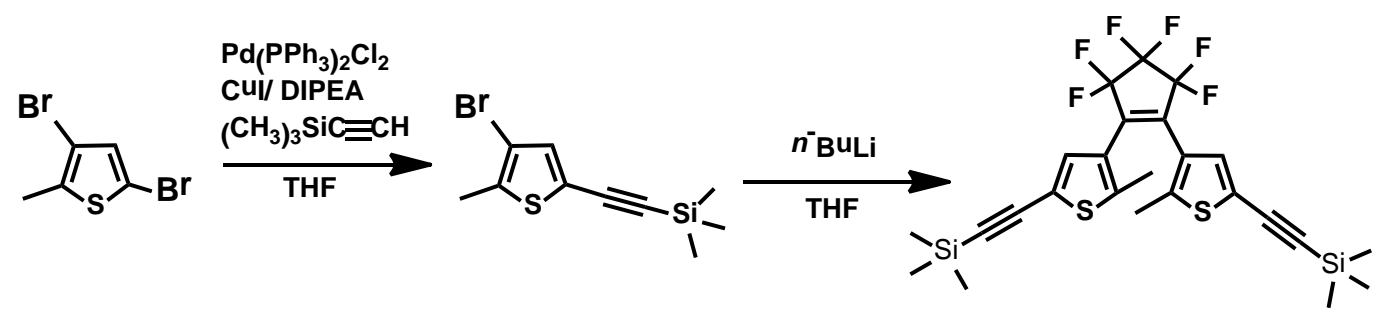

Scheme 2. The synthetic route of 10

\section{Results and discussion}

Photochromism of 1o. The photochromic propertie of 10 was measured. Fig. 1 shows the absorption spectra and color changes of 10 in hexane solution $\left(2.0 \times 10^{-5} \mathrm{~mol} \mathrm{~L}^{-1}\right)$. 10 exhibited a sharp absorption peak at $268 \mathrm{~nm}\left(\varepsilon=2.62 \times 10^{4} \mathrm{~L} \mathrm{~mol}^{-1} \mathrm{~cm}^{-1}\right)$. Upon irradiation with $297 \mathrm{~nm} \mathrm{UV} \mathrm{light,}$ the color of solution turned from colourless to blue, accompanied with a new broad absorption bands appeared at $583 \mathrm{~nm}\left(\varepsilon=6.79 \times 10^{3} \mathrm{~L} \mathrm{~mol}^{-1} \mathrm{~cm}^{-1}\right)$. This can be assigned to form the closed-ring isomer $1 c$. When $1 c$ was irradiated with visible light $(\lambda>510 \mathrm{~nm})$, the blue solution turned to colorless. This indicates that photochromism of 10 is reversible.

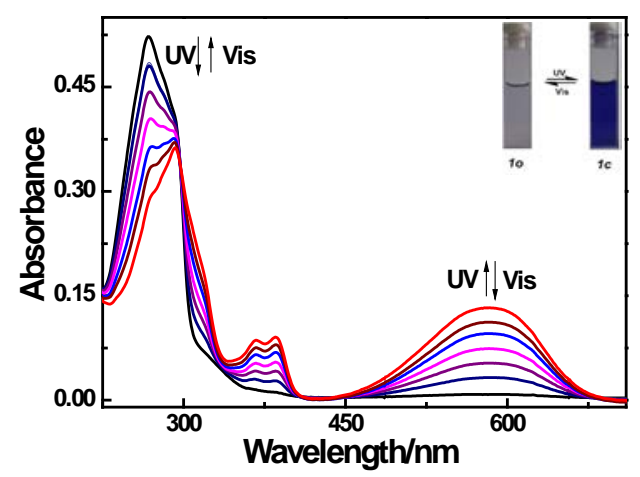

Fig. 1. Absorption spectra and color changes of 10

Photochromic reaction kinetics in hexane solution. Fig. 2. (A) / Fig. 2. (B) shows the photochromic cyclization / cycloreversion kinetics of 1 in hexane, respectively. The photochromic kinetics were obtained by photochromism of 10 upon irradiation with UV/Vis. It can be seen from Fig. 2. that the absorbance / $-\log (\mathrm{Abs})$ and exposal time have good linearity and the cyclization / cycloreversion processes of 10 belong to the zeroth / one order reaction. The reaction rate constant $(k)$ of 10 could been gained from the slope of every line in Fig. 2. (A) and Fig. 2. (B). Hence, the $k$ of cyclization $\left(k_{o-c}, 10^{-3}\right)$ /cycloreversion $\left(k_{c-o}, 10^{-2}\right)$ kinetics of 1 are $0.22 \mathrm{~mol} \mathrm{~L}^{-1} \mathrm{~s}^{-1}$ and $0.10 \mathrm{~s}^{-1}$, respectively.
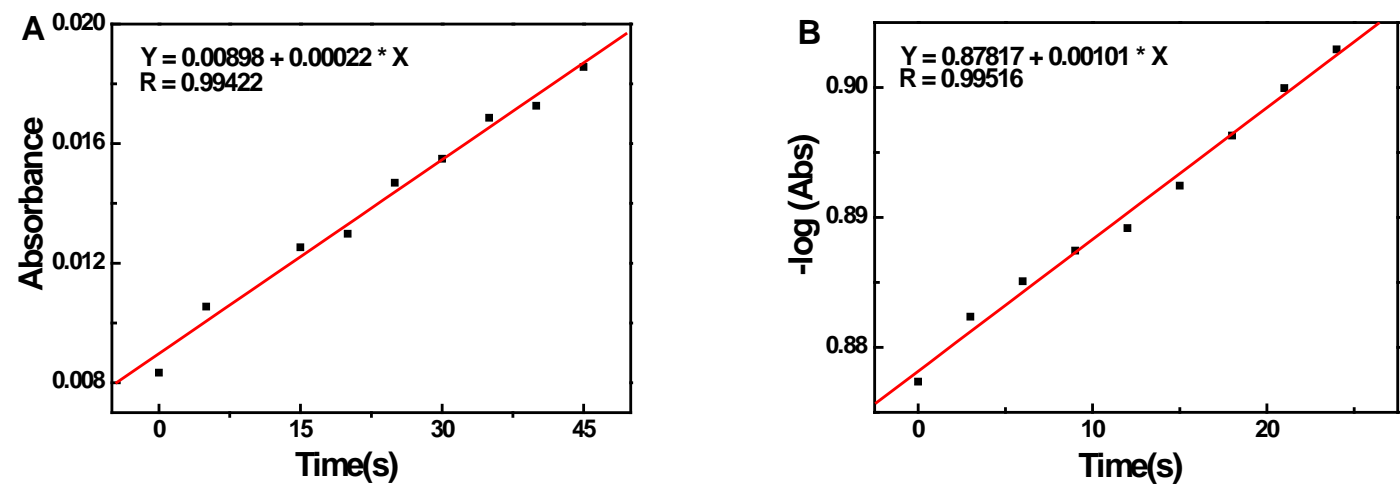

Fig. 2. The cyclization (A) and cycloreversion (B) kinetics of 1

Fluorescence of 1o. The fluorescence properties of 10 in hexane solution were measured. Fig. 3. shows the emission spectral changes of 10 at $459 \mathrm{~nm}$ in hexane $\left(2.0 \times 10^{-5} \mathrm{~mol} \mathrm{~L}^{-1}\right)$ upon 
photoirradiation with $297 \mathrm{~nm}$ light when excited at $290 \mathrm{~nm}$. Obviously, the fluorescence of 10 could be modulated by light, reversibly [12-14]. Once irradiated with $297 \mathrm{~nm}$ light, the emission intensity of 10 would decrease slowly along with the forming of closed-ring isomer [13]. When further irradiated with $297 \mathrm{~nm}$ light for $2 \mathrm{~min}$, the solution of 10 arrived at the photostationary state in hexane. At the same time, the emission intensity of 10 was quenched to ca. $70 \%$. Relatively, the fluorescence of 10 could be recovered by irradiation with appropriate visible light $(\lambda>510 \mathrm{~nm})$. Therefore, the fluorescent modulation efficiency of 10 was $30 \%$ in hexane.The result showed that the change of the emission intensity of 10 is reversible and 10 is useful for application as the fluorescence switches [14].

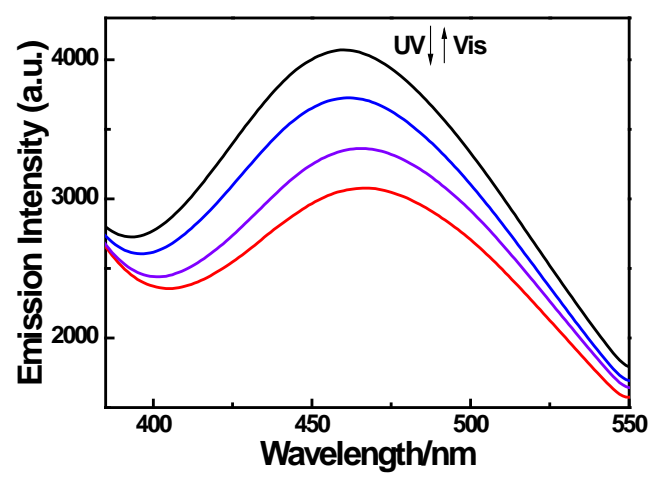

Fig. 3. Emission intensity changes of 10 upon irradiation with $297 \mathrm{~nm}$ UV light at room temperature in hexane $\left(2.0 \times 10^{-5} \mathrm{~mol} \mathrm{~L}^{-1}\right)$

\section{Summary}

In brief, a novel symmetrical diarylethene containing two 2- menthy l- 5- ( trimethylsilylacetylene)3-thienyl units has been successfully synthesized and fully characterized for the first time. The diarylethene exhibited excellent photochromism in solution. Meanwhile, the fluorescence of the open-ing diraylethene is much more stronger than closed-ring diraylethene. The results suggested that the diarylethene could apply to optical recording on account of their fascinating properties.

\section{Acknowledgement}

This work was supported by the financial support from the National Natural Science Foundation of China (21362013, 51373072).

\section{References}

[1] X. Zhang, H. Li, G. Liu, et al: Luminescence, vol. 62 (2016)

[2] R. Pohl, P. Anzenbacher: Organic letters, vol. 16 (2003) no. 5, p. 2769-2772.

[3] Q Luo, M Liu, R Cheng, et al: Dyes and Pigments, vol. 113 (2015), p. 602-608.

[4] H. Jia, S. Pu, C. Fan, et al: Spectrochimica Acta Part A: Molecular and Biomolecular Spectroscopy, vol. 138 (2015) no. 6917, p. 441-446.

[5] F. Duan, G. Liu, C. Fan, et al: Tetrahedron Letters, vol. 18 (2016) no. 57, p. 1963-1966

[6] X. Dong, R. Wang, G. Liu, et al: Tetrahedron, vol. 72 (2016) no. 22, p. 2935-2942.

[7] A Fihey, A Perrier, W.R.Browne, et al: Chemical Society Reviews, 2, vol. 11(2015) no. 44, p. 3719-3759.

[8] G. Liao, C. Zheng, D. Xue, et al: RSC Advances, vol. 41 (2016) no. 6, p. 34748-34753.

[9] S. Pu, C. Zhang, C. Fan, et al: Dyes and Pigments, vol. 129 (2016), p. 24-33.

[10]S.Z. Pu, Q. Sun, C.B. Fan, et al: Journal of Materials Chemistry C, vol. 15 (2016) no. 4, p. 3075-3093. 
[11]C.C. Warford, C.J. Carling, N.R. Branda: Chemical Communications, vol. 32 (2015) no. 15, p. 7039-7042.

[12]W. Geng, C. Zheng, S. Cui, et al: Journal of Photochemistry and Photobiology A: Chemistry, Tetrahedron, vol. 282 (2014) no. 10, p. 47-52.

[13]A.D. Dubonosov, V.A. Bren, V.I. Minkin, et al: Tetrahedron, vol. 46 (2015) no. 71, p. 8817-8822.

[14]T. Hu, Li. Z, T. Wang, et al: Journal of Heterocyclic Chemistry, vol. (2015). 